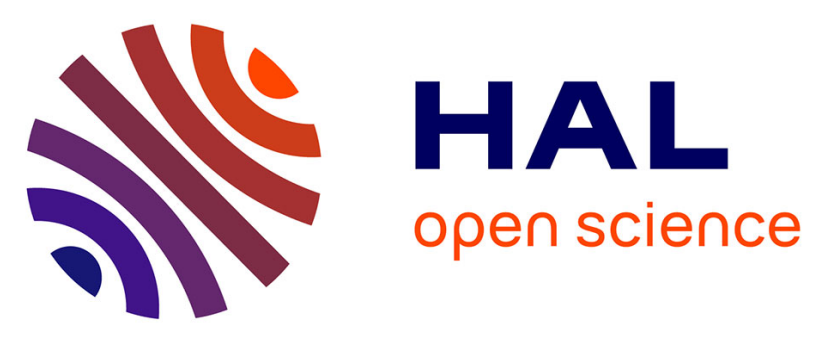

\title{
Alcohol intake and risk of acute coronary syndrome and mortality in men and women with and without hypertension
}

Jane Lindschou Hansen, Janne Schurmann Tolstrup, Majken Karoline Jensen, Morten Grønbæk, Anne Tjønneland, Erik Berg Schmidt, Kim Overvad

\section{To cite this version:}

Jane Lindschou Hansen, Janne Schurmann Tolstrup, Majken Karoline Jensen, Morten Grønbæk, Anne Tjønneland, et al.. Alcohol intake and risk of acute coronary syndrome and mortality in men and women with and without hypertension. European Journal of Epidemiology, 2011, 26 (6), pp.439-447. 10.1007/s10654-011-9564-7 . hal-00680249

\section{HAL Id: hal-00680249 \\ https://hal.science/hal-00680249}

Submitted on 19 Mar 2012

HAL is a multi-disciplinary open access archive for the deposit and dissemination of scientific research documents, whether they are published or not. The documents may come from teaching and research institutions in France or abroad, or from public or private research centers.
L'archive ouverte pluridisciplinaire HAL, est destinée au dépôt et à la diffusion de documents scientifiques de niveau recherche, publiés ou non, émanant des établissements d'enseignement et de recherche français ou étrangers, des laboratoires publics ou privés. 


\section{Alcohol intake and risk of acute coronary syndrome and mortality in men and women with and without hypertension}

Short title: Alcohol, hypertension and acute coronary syndrome

Jane Lindschou Hansen, Janne S. Tolstrup, Majken K. Jensen, Morten Grønbæk, Anne Tjønneland, Erik Berg Schmidt, Kim Overvad

\section{Corresponding Author:}

Janne S. Tolstrup

National Institute of Public Health, University of Southern Denmark, Øster Farimagsgade 5A, 2.,

DK-1399 Copenhagen K, Denmark

e-mail: jst@niph.dk

J Lindschou Hansen, M Grønbæk

Centre for Alcohol Research, National Institute of Public Health, University of Southern Denmark, Copenhagen, Denmark

MK Jensen

Department of Nutrition, Harvard School of Public Health, Boston, MA, USA

A Tjønneland

Danish Cancer Society, Institute of Cancer Epidemiology, Copenhagen, Denmark

E Berg Schmidt, K Overvad

Department of Cardiology, Center for Cardiovascular Research, Aalborg Hospital, Aarhus University Hospital, Denmark).

K Overvad

Department of Clinical Epidemiology, Aalborg Hospital, Aarhus University Hospital, Aalborg, Denmark . 
Although a light to moderate alcohol intake is associated with a lower risk of acute coronary syndrome (ACS), alcohol is also associated with risk of hypertension, which in turn is a strong risk factor of ACS. We examined whether middle-aged men and women with hypertension also benefit from a light to moderate alcohol intake in relation to risk of ACS and overall mortality. We used data from 57,053 men and women, aged 50-64, who participated in the Danish Diet, Cancer and Health study. Information on alcohol intake (amount and frequency) was reported by the participants. Hypertension status was assessed at baseline by combining blood pressure measurements and self-reports. During follow-up, 860 and 271 ACS events occurred among men and women. Irrespective of alcohol intake, participants with hypertension had a higher risk than participants with normal blood pressure. Alcohol intake was associated with a lower risk of ACS among participants both with and without hypertension and there was no evidence of interaction between alcohol intake and hypertension. Those who drank moderately had a lower mortality than abstainers and those who drank heavily; and for all levels of alcohol intake, participants with hypertension had a higher risk than participants with normal blood pressure. Results were similar for men and women. These findings indicate that a light to moderate alcohol intake has similar effects on the risk of ACS in men and women with and without hypertension. 


\section{Introduction}

Hypertension is a serious public health problem, causing almost $13 \%$ of all deaths worldwide and $17 \%$ of all deaths in high income countries [1]. Heavy alcohol consumption is associated with an increased risk for hypertension [2], and hypertension in itself is a major risk factor for coronary heart disease [3]. On the other hand, substantial epidemiological evidence suggests that alcohol intake has beneficial effects on the cardiovascular system, causing a lower risk of coronary heart disease among light to moderate alcohol drinkers compared with abstainers $[4,5]$. The beneficial effect is believed mainly to be due to increasing levels of high-density lipoprotein cholesterol, decreased fibrinogen and increased insulin sensitivity [6-8].

The association between alcohol intake and coronary heart disease and total mortality with respect to hypertension has been examined in earlier studies [9-15], but important questions remain. First, apart from one these studies were restricted to individuals with hypertension, thus risks comparison with individuals without hypertension is not possible [15]. Second, none of the studies investigating the risk of coronary heart disease included both men and women. Women differ from men in alcohol pharmacokinetics (i.e., processing and elimination of alcohol in the body) and the level of alcohol intake beyond which the risk of adverse effects increases is lower in women than in men $[16,17]$. Also, sex differences in the effect of a range of cardiovascular risk factors, including hypertension, have been observed, which further underlines the importance of studying the differences between men and women [18].

Our aim was to address if the current sensible drinking guidelines for moderate drinking apply to middle-aged women and men regardless of whether they have hypertension or not. Therefore, we investigated the association between alcohol intake and the incidence of acute coronary syndrome and total mortality in a large Danish cohort of men and women with and without hypertension. 


\section{Methods}

The Diet, Cancer and Health study

Between December 1993 and May 1997, 160,725 Danish adults aged 50-64 years were invited to participate in the Diet, Cancer and Health study. Eligible participants were born in Denmark and had no previous cancers. In total, $35 \%$ of the invited agreed to participate $(27,178$ men and 29,875 women).

Prior to a clinic visit, the participants filled in a comprehensive 192-item food frequency questionnaire (FFQ) including questions about amount of alcohol intake. While at the clinic, they filled in an additional questionnaire concerning health behavioural and social factors, as well as questions regarding the frequency of alcohol intake. Both questionnaires were checked for misunderstandings and inconsistencies by an interviewer. Anthropometrical measures and blood pressure were taken on site [19].

\section{Alcohol intake}

In the food frequency questionnaire, participants reported average alcohol intake during the past year. Intake was reported for 6 different types of alcoholic beverages: Light, regular and strong beer (in bottles), wine (in glasses), fortified wine (in drinks) and spirits (in drinks) in predefined categories from "never" to "8 or more" drinks per day. The different types of alcoholic beverages had different alcohol content: light beer, $8.9 \mathrm{~g}$ ethanol; regular beer, $12.2 \mathrm{~g}$ ethanol; strong beer, $17.5 \mathrm{~g}$ ethanol; wine, $12.2 \mathrm{~g}$ ethanol; fortified wine, $9.3 \mathrm{~g}$ ethanol; and spirits $9.9 \mathrm{~g}$ ethanol [20]. The alcohol content for each type was summed up, and a weekly amount of alcohol intake was calculated in number of drinks containing $12 \mathrm{~g}$ alcohol each. Drinking frequency was reported in the background questionnaire in predefined categories; "never", "less than once a month", "1-3 times monthly", “once a week”, “2-4 times weekly”, "5-6 times weekly” and "daily”. 


\section{Hypertension}

In the background questionnaire, participants were asked if they had been diagnosed with hypertension. Participants, who had answered yes, were categorized as having "self-reported hypertension". Among these, participants who additionally answered that they were or had been taking any medication for hypertension were categorized as "using medication". In addition, participants had their blood pressure measured during the clinic visit. Blood pressure was measured once in a lying position after 5 minutes of rest [19]. Participants who had a systolic blood pressure above $140 \mathrm{~mm} \mathrm{Hg}$ and diastolic blood pressure above $90 \mathrm{~mm} \mathrm{Hg}$ were categorized as having "measured hypertension" [21]. We used both selfreports and measures of high blood pressure to define hypertension. In total, 8,722 (34\%) men and 8,216 (28\%) women were categorized as having hypertension (1,506 men and 2,860 women by selfreport only, 4,966 men and 3,171 women by measurement of blood pressure only, and 2,250 men and 2,185 women by both criteria).

\section{Follow-up}

Information about incident cases of acute coronary syndrome (ACS), including fatal and non-fatal myocardial infarction (MI), sudden cardiac death and unstable angina pectoris was obtained by linkage with central Danish registries of hospital discharges and causes of death (ICD-8 codes 410-410.99, 427.27 and ICD-10 codes I20.0, I21.0-21.9, I46.0-46.9). ACS cases were identified between baseline and January 1, 2004, which is the date of the last available update from the Hospital Discharge Register. As described elsewhere [22], all discharge diagnoses were retrieved and reviewed to ensure that they met the criteria for ACS, proposed by the American Heart Association and the European Society of Cardiology [23]. Our validation study confirmed that MI is recorded with a high degree of validity in this register (positive predictive value for diagnoses received upon discharge from a ward $=92 \%$ ), whereas unstable angina and cardiac arrest were less 
accurate $(<=50 \%)$ [22]. Through the Causes of Death Registry, we additionally identified 111 participants with fatal MI.

In a sub-analyses, we excluded participants who had received the ACS diagnosis based on reports of unstable angina or cardiac arrest $(n=235)$. This analysis did not change the results using the global ACS diagnosis, which we report in the present paper.

Person-years are recorded from the date of participant enrolment to the date of coronary event $(n=1,131)$, death from other causes $(n=2,410)$, emigration $(n=215)$, loss to follow-up $(n=5)$ or January 1, 2004 which was the last day of follow-up, whichever came first.

Total mortality was the secondary outcome in this study. Cases were identified through the Danish Civil Registration System where vital status is registered for every citizen. The cohort is currently followed up until July 2006, and person-years are recorded from the date of enrolment to this date or date of censoring. Prior to this date, 4,210 people died, 311 emigrated and 6 were lost to follow-up.

\section{Statistical analysis}

We calculated hazard ratios (HR) by Cox proportional hazard regression analysis using the statistical package STATA version 10. Age was used as time axis with delayed entry implemented to ensure maximal adjustment for confounding by age. We addressed the joint effects of alcohol intake and BP status on risk of ACS by using light drinking participants (1-6 drinks per week) with normal blood pressure as reference category. Analyses were performed for the exposures weekly alcohol intake and drinking frequency, and for the outcomes ACS and total mortality.

For ACS we calculated crude risk estimates and risk estimates adjusted for the following potential confounders: Smoking (never, ex (stop before/after age 30), 1-14, 15-24, or 25+ g tobacco per day), body mass index (BMI, $<18.5,18.5-25,25-30,30+\mathrm{kg} / \mathrm{m}^{2}$ ), waist circumference $(\mathrm{cm})$, school education $(\leq 7,8-10$, or $10+$ years in school), physical activity in leisure time (hours per week), intake of fruit (quartiles, grams), vegetables (grams), fish (grams), fat (quartiles, \% of 
total energy intake), saturated fat (\% of total energy intake), and menopausal status and use of hormone replacement therapy (HRT) in women (pre-, unsure, postmenopausal not using HRT and postmenopausal using HRT), self-reported diabetes mellitus (yes/no) and self-reported hypercholesterolemia (yes/no).

We tested the proportional hazards assumption and no violations were found. When testing for linear trend, we analyzed the median value within categories continuously. Statistical interactions between alcohol intake and hypertension, and alcohol intake and sex were assessed on the multiplicative scale by comparing the log likelihoods in nested models with and without crossproduct terms.

To test whether participants taking medication for hypertension had similar risks of ACS and total mortality as those with normal blood pressure, we compared the relative risks according to alcohol intake in participants with hypertension that were medicated to those classified as normotensives. We also compared those with self-reported hypertension and those with measured hypertension to those with normal blood pressure.

To examine the possible bias due to undiagnosed cardiovascular illness at baseline, which might have influenced the participants' alcohol intake, we carried out analyses for the first 2 and 4 years of follow-up, which we compared with analyses of the subsequent years of follow-up.

We excluded participants with missing information on relevant questionnaire data $(n=484)$, ACS diagnosis before baseline $(n=994)$ and participants who were registered with an ACS diagnosis during follow-up, but whose medical record could not be retrieved and whose endpoint therefore could not be validated were excluded ( $n=113)$. In total, 26,035 men and 29,427 women were eligible for further analyses.

\section{Results}

Five percent of the men and $16 \%$ of the women were nondrinkers $(<1$ drink/week). Among the remaining participants the median alcohol intake was 12.1 drinks/week for men and 6.6 
drinks/week for women. Participants in the lowest and in the highest drinking categories were more likely to be smokers and to suffer from hypercholesterolemia than participants in the inbetween drinking categories (Table 1). The prevalence of diabetes and a short school education were highest among the nondrinkers. The above trends were the same for women and men.

During a mean follow-up of 7.6 years, 860 and 271 incident cases of ACS occurred among men and women. In adjusted analyses, the amount of alcohol intake was inversely associated with risk of ACS, however only statistically significant among men ( $\mathrm{p}$ for trend: men $<0.001$, women=0.11) (Table 2). The lowest risk was observed among the men and women in the highest alcohol drinking categories (28+ and 21+ drinks/week, corresponding to 48+ and 36+ grams/day). Compared to light drinkers (1-6 drinks/week), the risks among men and women in the top alcohol consumption groups were 0.68 (95\% CI: 0.53-0.91) and 0.64 (95\% CI: 0.38-1.09), respectively.

We next studied the associations between alcohol intake and ACS among men and women with and without hypertension. In men and women, a higher alcohol intake was associated with a lower risk of ACS regardless of hypertensive status, however only statistically significant among men (Table 3). Approximately half of the ACS events occurred among participants with hypertension $(47 \%(\mathrm{n}=402)$ among men and $51 \%(\mathrm{n}=137)$ among women). We found no evidence of interaction between sex and alcohol intake on risk of ACS in participants with or without hypertension $(\mathrm{p}=0.40$ and $\mathrm{p}=0.56)$. To study the associations between alcohol intake and ACS risk according to different definitions of hypertension, we modelled men and women together with a joint reference group consisting of light drinkers without hypertension (Figure 1). Hypertension was investigated by selfreports (all), by blood pressure measurements (alone), and by selfreported use of antihypertensive medication. For all definitions of hypertensive status, we observed an inverse relationship between alcohol intake and risk of ACS (Figure 1). Compared with participants in the same alcohol category without hypertension, participants in the hypertension group consistently had a higher risk of ACS, at all levels of alcohol intake. There was no evidence of interaction between alcohol intake and hypertension in any of the models. Compared with 
participants with normal blood pressure, the relative risks for ACS among participants according to different definitions of hypertension were 1.63 (95\% CI, 1.44-1.85; self-report and measurements combined), 1.46 (95\% CI, 1.18-1.81; self-report (all)), 1.47 (95\% CI, 1.26-1.72; measured (only)), and 1.79 (95\% CI, 1.52-2.11; use of antihypertensive medication).

All analyses were repeated incorporating alcohol drinking frequency instead of the average amount of alcohol intake. Results were comparable to results reported above using quantity and we saw no signs of interactions between alcohol intake frequency and hypertension status.

All-cause mortality risk according to alcohol intake was $\mathrm{J}$-shaped in men and women (data not shown). In analyses including hypertension, the association between alcohol and risk of mortality was also J-shaped and the risk among participants with hypertension was higher than for participants without hypertension at all levels of alcohol intake (Figure 2).

Finally, to examine the possibility that baseline symptoms of preclinical disease might have caused a reduction in alcohol intake, and thereby biasing the results, we conducted analyses comparing the association between alcohol intake and ACS only including early cases (i.e. cases that occurred within the first two years of follow up, $n=212$ ) with the association including only later cases (cases $n=919$ ). There was an inverse association between drinking frequency and coronary heart disease in both groups. For early cases, multivariate hazard ratios for men and women who drank 21-27 drinks/week and 28+ drinks/week were 0.59 (0.31-0.89) and 0.53 (0.310.89) compared with drinking 1-6 drinks/week, and for later cases, multivariate hazard ratios for drinking 21-27 drinks/week and 28+ drinks/week were 0.74 (0.57-0.95) and 0.74 (0.58-0.93).

\section{Discussion}

In this prospective study of middle-aged men and women, moderate alcohol intake was associated with a lower risk of acute coronary syndrome (ACS) in men and women with and without hypertension. For all studied associations (amount and frequency of alcohol intake), the risk of ACS and of all-cause mortality among participants with hypertension was higher than among 
participants without hypertension. There was no indication of interaction between alcohol intake and hypertension on the risk of ACS.

To our knowledge, this is the first study that includes both men and women, includes both normotensives and hypertensives, and assesses both incident ACS and total mortality as outcome measures.

In agreement with our results, previous studies including individuals with hypertension reported inverse associations between alcohol intake and coronary heart disease [9-11, 15]. No comparisons were made with normotensive individuals. Total mortality has been investigated in prior studies [9, 12-14, 24], but with inconsistent conclusions about the potential beneficial effects of a light-to-moderate alcohol intake in men with hypertension $[9,14]$. We found that moderate drinkers had a lower all-cause mortality than non-drinkers and heavy drinkers, which seems to apply to both men and women with normal blood pressure and hypertension. Furthermore, we did not find any evidence of interaction between alcohol intake and hypertension which is in agreement with results of another study [10]. This was consistently observed among men and women, for ACS and total mortality, for different definitions of hypertension and for alcohol intake, evaluated both as average quantity and frequency. This consistency strengthens the findings, and is therefore less likely to be caused by bias.

A strength of our study is the Danish complete registration system, which allows us to have complete follow-up and that we used validated information on ACS. The coverage of the Danish registration system is very high, with virtually every event recorded [25, 26]. All discharge diagnoses of ACS were validated and only confirmed cases were included in the present analyses. Due to limited information available, the 111 ACS diagnoses obtained from the Cause of Death Register are less accurate.

Another strength in our study is the large variation in alcohol intake. This means that we were able to describe the risk of ACS and total mortality associated with a wide range of alcohol intake and making results applicable to the whole Danish population. 
A limitation in our study is the study participation rate of only $35 \%$. People who chose to participate may have a different risk profile and be at better health than those who declined participation. A comparison between study participants and those who declined, showed that study participants on average had a higher income, higher level of education, larger size housing and were more likely to be married [19]. This confirms the assumption that lower socioeconomic groups are underrepresented in epidemiological studies. However, the observed incidence of coronary heart disease within the study cohort did not differ from that of the general Danish population [27]. We observed similar tendencies among men and women, although, the number of cases was substantially lower among women than among men, and hence results for women are less certain and warrant further study.

Alcohol intake was reported in a food frequency questionnaire. The food frequency questionnaire has been found valid when comparing it to formal dietary interviews in Danish populations [28]. However, alcohol intake in other studies has shown to change over time. One study reported that the U-shaped association between alcohol and total mortality shifted after adjusting for intake variation [29], while another study reported the U-shaped association to be consistent for those with a stable alcohol intake [30]. In our study, we applied a single measure of alcohol intake, which could potentially bias our results. Also, alcohol intake could be misclassified among the participants who were diagnosed with high blood pressure during the clinic visit: it is possible, that such participants change their lifestyle and habits, including alcohol intake, due to this information. However, Beulens et al. measured alcohol intake several times, and they found that alcohol intake before and after diagnosis of hypertension was highly correlated [9].

Due to the low numbers of cases in the non-drinking category, it was not possible to analyse never drinkers and ex-drinkers separately. If the group of non-drinkers primarily consists of exdrinkers, the excess risk associated with non-drinking might be due to the fact that ex-drinkers could have been "sick quitters" [31]. The analyses were not adjusted for participants' medical history, which means that the increased risk of ACS and total mortality among nondrinkers could 
be caused by latent illness. However, participants with a history of ACS were excluded so this is unlikely to be the case. Also, we did measure alcohol intake in many different categories, and the inverse associations were not only driven by a relatively high risk of ACS and death among nondrinkers. Furthermore, when analysing early and later cases separately (defined as cases occurring before and after two years of follow up), inverse associations between alcohol and ACS were consistently observed, and it is thus unlikely that the sick-quitting are causing the observed results.

We avoided the term 'binge drinking', which in most studies is defined as drinking a minimum number of drinks per occasion such as 6 or $13[32,33]$, because the participants were not asked directly about occasional heavy drinking, and we can therefore not comment on this.

We used very similar definitions of hypertension as Bos et al. and Britton [10, 11]. However, obtaining information about participants' hypertension status can be problematic. The measurements can be misclassified because it was only measured once, and some people tend to have elevated blood pressure in the presence of a physician, so called white coat hypertension [21]. Thus some individuals might be wrongly categorized as hypertensive at baseline. Despite these possibilities of measurement error, we found consistent results, when analyzing people with measured hypertension, self-reported hypertension and self-reported treatment for hypertension separately. When studying alcohol intake and risk of CHD, it is a concern that any decrease in risk of coronary heart events due to alcohol intake will be outweighed by an increase in other diseases or problems related to alcohol intake, e.g., liver diseases, cancers and road crashes. Our study showed that the overall risk of mortality was lowest for participants with a moderate alcohol intake, and it therefore appears that the cardioprotective effect outweighs the damaging effects associated with moderate alcohol intake. This result is, however, restricted to middle-aged men and women. 


\section{Conclusions}

We found inverse associations between alcohol intake and ACS and a J-shaped association for total mortality among both hypertensives and individuals with normal blood pressure. This implies that the current sensible drinking guidelines for moderate drinking also apply to middle-aged women and men regardless of whether they have hypertension or not. This result further implies that people with hypertension who drink alcohol lightly to moderately do not need to reduce their alcohol intake in order to reduce their risk of ACS. It also implies that those who drink heavily should reduce their alcohol intake in order to reduce their risk of mortality from all causes. However, this does not mean that nondrinkers should be encouraged to drink alcohol in order to prevent ACS and prolong life: many detrimental consequences are associated with alcohol intake [21], and it would be unethical to advise people to increase their alcohol intake or even to start drinking alcohol if they do not do so already.

Acknowledgements This study was supported by grants from the Health Insurance Foundation and the Danish Cancer Society. 
1. World Health Organization. GLOBAL HEALTH RISKS, Mortality and burden of disease attributable to selected major risks. 2009.

2. Keil U, Liese A, Filipiak B, Swales JD, Grobbee DE. Alcohol, blood pressure and hypertension. Novartis Found Symp 1998;216:125-144.

3. Yusuf S, Hawken S, Ounpuu S, Dans T, Avezum A, Lanas F, McQueen M, Budaj A, Pais P, Varigos J, Lisheng L. Effect of potentially modifiable risk factors associated with myocardial infarction in 52 countries (the INTERHEART study): case-control study. Lancet 2004 Sep 11;364(9438):937-952.

4. Collins MA, Neafsey EJ, Mukamal KJ, Gray MO, Parks DA, Das DK, Korthuis RJ. Alcohol in moderation, cardioprotection, and neuroprotection: epidemiological considerations and mechanistic studies. Alcohol Clin Exp Res 2009 Feb;33(2):206-219.

5. Corrao G, Rubbiati L, Bagnardi V, Zambon A, Poikolainen K. Alcohol and coronary heart disease: a meta-analysis. Addiction 2000 Oct;95(10):1505-1523.

6. Agarwal DP. Cardioprotective effects of light-moderate consumption of alcohol: a review of putative mechanisms. Alcohol Alcohol 2002 Sep;37(5):409-415.

7. Mukamal KJ, Jensen MK, Gronbaek M, Stampfer MJ, Manson JE, Pischon T, Rimm EB. Drinking frequency, mediating biomarkers, and risk of myocardial infarction in women and men. Circulation 2005 Sep 6;112(10):1406-1413.

8. Rimm EB, Moats C. Alcohol and Coronary Heart Disease: Drinking Patterns and Mediators of Effect. 17 ed. 2007. p. S3-S7.

9. Beulens JW, Rimm EB, Ascherio A, Spiegelman D, Hendriks HF, Mukamal KJ. Alcohol consumption and risk for coronary heart disease among men with hypertension. Ann Intern Med 2007 Jan 2;146(1):10-19.

10. Bos S, Grobbee DE, Boer JM, Verschuren WM, Beulens JW. Alcohol consumption and risk of cardiovascular disease among hypertensive women. Eur J Cardiovasc Prev Rehabil 2009 Dec 31 .

11. Britton KA, Gaziano JM, Sesso HD, Djousse L. Relation of alcohol consumption and coronary heart disease in hypertensive male physicians (from the Physicians' Health Study). Am J Cardiol 2009 Oct 1;104(7):932-935.

12. Freiberg MS, Chang YF, Kraemer KL, Robinson JG, ms-Campbell LL, Kuller LL. Alcohol consumption, hypertension, and total mortality among women. Am J Hypertens 2009 Nov;22(11):1212-1218.

13. Malinski MK, Sesso HD, Lopez-Jimenez F, Buring JE, Gaziano JM. Alcohol consumption and cardiovascular disease mortality in hypertensive men. Arch Intern Med $2004 \mathrm{Mar}$ 22;164(6):623-628.

14. Palmer AJ, Fletcher AE, Bulpitt CJ, Beevers DG, Coles EC, Ledingham JG, Petrie JC, Webster J, Dollery CT. Alcohol intake and cardiovascular mortality in hypertensive patients: 
report from the Department of Health Hypertension Care Computing Project. J Hypertens 1995 Sep;13(9):957-964.

15. Reims HM, Kjeldsen SE, Brady WE, Dahlof B, Devereux RB, Julius S, Beevers G, De FU, Fyhrquist F, Ibsen H, Kristianson K, Lederballe-Pedersen O, Lindholm LH, Nieminen MS, Omvik P, Oparil S, Wedel H. Alcohol consumption and cardiovascular risk in hypertensives with left ventricular hypertrophy: the LIFE study. J Hum Hypertens 2004 Jun;18(6):381-389.

16. White IR, Altmann DR, Nanchahal K. Alcohol consumption and mortality: modelling risks for men and women at different ages. BMJ 2002 Jul 27;325(7357):191.

17. Mumenthaler MS, Taylor JL, O'Hara R, Yesavage JA. Gender differences in moderate drinking effects. Alcohol Res Health 1999;23(1):55-64.

18. Anand SS, Islam S, Rosengren A, Franzosi MG, Steyn K, Yusufali AH, Keltai M, Diaz R, Rangarajan S, Yusuf S. Risk factors for myocardial infarction in women and men: insights from the INTERHEART study. Eur Heart J 2008 Apr;29(7):932-940.

19. Tjonneland A, Olsen A, Boll K, Stripp C, Christensen J, Engholm G, Overvad K. Study design, exposure variables, and socioeconomic determinants of participation in Diet, Cancer and Health: a population-based prospective cohort study of 57,053 men and women in Denmark. Scand J Public Health 2007;35(4):432-441.

20. Tjonneland A, Thomsen BL, Stripp C, Christensen J, Overvad K, Mellemkaer L, Gronbaek $\mathrm{M}$, Olsen JH. Alcohol intake, drinking patterns and risk of postmenopausal breast cancer in Denmark: a prospective cohort study. Cancer Causes Control 2003 Apr;14(3):277-284.

21. Pickering TG, Hall JE, Appel LJ, Falkner BE, Graves J, Hill MN, Jones DW, Kurtz T, Sheps SG, Roccella EJ. Recommendations for blood pressure measurement in humans and experimental animals: Part 1: blood pressure measurement in humans: a statement for professionals from the Subcommittee of Professional and Public Education of the American Heart Association Council on High Blood Pressure Research. Hypertension 2005 Jan;45(1):142-161.

22. Joensen AM, Jensen MK, Overvad K, Dethlefsen C, Schmidt E, Rasmussen L, Tjonneland A, Johnsen S. Predictive values of acute coronary syndrome discharge diagnoses differed in the Danish National Patient Registry. J Clin Epidemiol 2008 Aug 20.

23. Luepker RV, Apple FS, Christenson RH, Crow RS, Fortmann SP, Goff D, Goldberg RJ, Hand MM, Jaffe AS, Julian DG, Levy D, Manolio T, Mendis S, Mensah G, Pajak A, Prineas RJ, Reddy KS, Roger VL, Rosamond WD, Shahar E, Sharrett AR, Sorlie P, Tunstall-Pedoe H. Case definitions for acute coronary heart disease in epidemiology and clinical research studies: a statement from the AHA Council on Epidemiology and Prevention; AHA Statistics Committee; World Heart Federation Council on Epidemiology and Prevention; the European Society of Cardiology Working Group on Epidemiology and Prevention; Centers for Disease Control and Prevention; and the National Heart, Lung, and Blood Institute. Circulation 2003 Nov 18;108(20):2543-2549.

24. Renaud SC, Gueguen R, Conard P, Lanzmann-Petithory D, Orgogozo JM, Henry O. Moderate wine drinkers have lower hypertension-related mortality: a prospective cohort study in French men. Am J Clin Nutr 2004 Sep;80(3):621-625. 
25. Andersen TF, Madsen M, Jorgensen J, Mellemkjoer L, Olsen JH. The Danish National Hospital Register. A valuable source of data for modern health sciences. Dan Med Bull 1999 Jun;46(3):263-268.

26. Juel K, Helweg-Larsen K. The Danish registers of causes of death. Dan Med Bull 1999 Sep;46(4):354-357.

27. Tolstrup J, Jensen MK, Tjonneland A, Overvad K, Mukamal KJ, Gronbaek M. Prospective study of alcohol drinking patterns and coronary heart disease in women and men. BMJ 2006 May 27;332(7552):1244-1248.

28. Grønbæk M, Heitmann BL. Validity of self-reported intakes of wine, beer and spirits in population studies. Eur J Clin Nutr 1996 Jul;50(7):487-490.

29. Emberson JR, Shaper AG, Wannamethee SG, Morris RW, Whincup PH. Alcohol intake in middle age and risk of cardiovascular disease and mortality: accounting for intake variation over time. Am J Epidemiol 2005 May 1;161(9):856-863.

30. Grønbæk M, Johansen D, Becker U, Hein HO, Schnohr P, Jensen G, Vestbo J, Sørensen TI. Changes in alcohol intake and mortality: a longitudinal population-based study.

Epidemiology 2004 Mar;15(2):222-228.

31. Wannamethee SG, Shaper AG. Lifelong teetotallers, ex-drinkers and drinkers: mortality and the incidence of major coronary heart disease events in middle-aged British men. Int $J$ Epidemiol 1997 Jun;26(3):523-531.

32. Laatikainen T, Manninen L, Poikolainen K, Vartiainen E. Increased mortality related to heavy alcohol intake pattern. J Epidemiol Community Health 2003 May;57(5):379-384.

33. Malyutina S, Bobak M, Kurilovitch S, Gafarov V, Simonova G, Nikitin Y, Marmot M. Relation between heavy and binge drinking and all-cause and cardiovascular mortality in Novosibirsk, Russia: a prospective cohort study. Lancet 2002 Nov 9;360(9344):1448-1454. 


\section{Figure legends}

Fig. 1 Hazard ratios of acute coronary syndrome (ACS) relative to joint reference category of no hypertension and alcohol intake of 1-6 drinks/week in men and women combined and according to different definitions of hypertension. Multivariable adjusted for age, sex, smoking, school education, BMI, waist circumference, physical activity, intake of fruit, vegetables, fish, fat and saturated fat, hypercholesterolemia, diabetes, and for women: menopausal status and use of HRT.

- Squares represent participants with hypertension

- Circles represent participants with normal blood pressure

Fig. 2 Hazard ratios of all-cause mortality relative to joint reference category of no hypertension and alcohol intake of 1-6 drinks/week in men and women and according to hypertension. Multivariable adjusted for age, sex, smoking, school education, BMI, waist circumference, physical activity, intake of fruit, vegetables, fish, fat and saturated fat, hypercholesterolemia, diabetes, and for women: menopausal status and use of HRT.

- Squares represent participants with hypertension

- Circles represent participants with normal blood pressure 
Table 1 Characteristics according to alcohol intake in 26,035 men and 29,427 women in the Diet, Cancer and Health Study ${ }^{a}$

\begin{tabular}{|c|c|c|c|c|c|c|c|}
\hline & \multicolumn{7}{|c|}{ Alcohol Intake (drinks per week ${ }^{\mathrm{b}}$ ) } \\
\hline & $<1$ & $1-6$ & $7-13$ & $14-20$ & $21-27 / 21+^{\mathrm{c}}$ & $28+$ & $P^{\mathrm{d}}$ \\
\hline \multicolumn{8}{|l|}{ Men } \\
\hline Participants, $n$ & 1,284 & 6,651 & 6,974 & 3,093 & 3,542 & 4,491 & \\
\hline Age, y & $56.3(51-64)$ & $56.2(51-64)$ & $56.0(51-64)$ & $55.8(51-64)$ & $55.7(51-64)$ & $55.6(51-64)$ & 0.66 \\
\hline Hypertension, \% & 30 & 30 & 30 & 33 & 35 & 44 & $<0.001$ \\
\hline Current smokers, $\%$ & 37 & 37 & 33 & 37 & 39 & 53 & $<0.001$ \\
\hline BMI, $\mathrm{kg} / \mathrm{m}^{2}$ & $26.2(21-34)$ & $26.2(21-33)$ & $26.0(22-32)$ & $26.0(21-32)$ & $26.1(22-32)$ & $26.4(21-34)$ & 0.30 \\
\hline Waist circumference, $\mathrm{cm}$ & $95(79-116)$ & $95(81-114)$ & $95(81-112)$ & $95(82-112)$ & $95(82-112)$ & $97(82-116)$ & $<0.001$ \\
\hline School education, $\% \leq 7 \mathrm{y}$ & 47 & 40 & 32 & 32 & 29 & 34 & $<0.001$ \\
\hline Physical activity, hrs/wk & $0(0-6)$ & $0(0-5.5)$ & $0(0-5.5)$ & $0.5(0-6)$ & $0.5(0-6)$ & $0(0-5.5)$ & 0.13 \\
\hline Fruit, grams/day & $140(13-571)$ & $149(26-497)$ & $152(29-456)$ & $139(21-453)$ & $138(23-450)$ & $108(14-410)$ & 0.49 \\
\hline Vegetables, grams/day & $125(29-373)$ & $142(45-336)$ & $158(54-340)$ & $159(49-355)$ & $163(54-339)$ & $142(44-336)$ & 0.49 \\
\hline Fish, grams/day & $34(4-106)$ & $38(11-94)$ & $43(14-97)$ & $43(13-99)$ & $44(15-100)$ & $43(13-104)$ & 0.48 \\
\hline Saturated fat, $\%^{\mathrm{e}}$ & $14(9-19)$ & $13(9-17)$ & $13(9-17)$ & $12(9-16)$ & $12(8-15)$ & $11(7-15)$ & 0.50 \\
\hline Diabetes, $\%$ & 6.3 & 2.9 & 1.9 & 2.8 & 1.9 & 2.5 & $<0.001$ \\
\hline Hypercholesterolemia, \% & 8.1 & 6.8 & 6.6 & 8.3 & 8.2 & 9.3 & $<0.001$ \\
\hline \multicolumn{8}{|l|}{ Women } \\
\hline Participants, $n$ & 4,643 & 13,252 & 6,174 & 2,713 & 2,645 & & \\
\hline Age, y & $57.1(51-64)$ & $56.3(51-64)$ & $56.1(51-64)$ & $55.7(51-64)$ & $55.7(51-64)$ & & 0.62 \\
\hline Hypertension, $\%$ & 31 & 26 & 27 & 29 & 35 & & $<0.001$ \\
\hline Current smokers, $\%$ & 38 & 29 & 30 & 37 & 36 & & $<0.001$ \\
\hline BMI, $\mathrm{kg} / \mathrm{m}^{2}$ & $25.8(20-37)$ & $25.1(20-34)$ & $24.3(20-32)$ & $23.9(20-32)$ & $24.4(20-32)$ & & 0.32 \\
\hline Waist circumference, $\mathrm{cm}$ & $83(67-109)$ & $80(67-103)$ & $79(67-100)$ & $79(67-100)$ & $81(68-102)$ & & $<0.001$ \\
\hline School education, $\% \leq 7 \mathrm{y}$ & 45 & 33 & 26 & 20 & 22 & & $<0.001$ \\
\hline Physical activity, hrs/wk & $0(0-4)$ & $1(0-4.5)$ & $1(0-5)$ & $1(0-5.5)$ & $0.5(0-5)$ & & 0.17 \\
\hline Fruit, grams/day & $196(29-621)$ & $211(44-577)$ & $199(42-525)$ & $181(31-514)$ & $156(26-494)$ & & 0.49 \\
\hline Vegetables, grams/day & $148(35-424)$ & $171(53-395)$ & $179(60-373)$ & $182(57-400)$ & $173(51-378)$ & & 0.49 \\
\hline Fish, grams/day & $30(7-84)$ & $35(11-84)$ & $38(13-85)$ & $36(12-84)$ & $38(13-85)$ & & 0.47 \\
\hline Saturated fat, $\%^{\mathrm{e}}$ & $13(8-17)$ & $12(8-17)$ & $12(8-16)$ & $11(7-15)$ & $11(7-15)$ & & 0.50 \\
\hline Diabetes, $\%$ & 2.8 & 1.4 & 1.1 & 1.1 & 1.1 & & $<0.001$ \\
\hline Hypercholesterolemia, \% & 7.3 & 5.8 & 5.4 & 6.0 & 6.2 & & $<0.001$ \\
\hline Postmenopausal, \% & 65 & 59 & 58 & 52 & 56 & & $<0.001$ \\
\hline
\end{tabular}


Table 2 Hazard ratios (95\% confidence intervals) for acute coronary syndrome according to amount of alcohol

\begin{tabular}{|c|c|c|c|c|c|c|c|}
\hline & \multicolumn{6}{|c|}{ Alcohol Intake (drinks per week ${ }^{\mathrm{a}}$ ) } & \multirow[b]{2}{*}{$P$ for trend ${ }^{c}$} \\
\hline & $<1$ & $1-6$ & $7-13$ & $14-20$ & $21-27 / 21+^{b}$ & $28+$ & \\
\hline \multicolumn{8}{|l|}{ Men } \\
\hline Events & 80 & 251 & 197 & 107 & 90 & 135 & \\
\hline Person-years & 9,328 & 49,911 & 52,456 & 23,307 & 26,685 & 33,806 & \\
\hline Age-adjusted & $1.66(1.29-2.14)$ & 1.00 & $0.76(0.63-0.92)$ & $0.94(0.75-1.18)$ & $0.71(0.56-0.90)$ & $0.85(0.69-1.05)$ & 0.008 \\
\hline Multivariate adjusted $^{d}$ & $1.47(1.14-1.89)$ & 1.00 & $0.82(0.68-0.99)$ & $0.95(0.76-1.20)$ & $0.71(0.55-0.91)$ & $0.68(0.53-0.91)$ & $<0.001$ \\
\hline \multicolumn{8}{|l|}{ Women } \\
\hline Events & 63 & 130 & 39 & 22 & 17 & - & \\
\hline Person-years & 36,071 & 102,200 & 47,453 & 20,660 & 20,294 & - & \\
\hline Age-adjusted & $1.25(0.92-1.69)$ & 1.00 & $0.67(0.47-0.95)$ & $0.89(0.57-1.41)$ & $0.71(0.43-1.18)$ & - & 0.033 \\
\hline Multivariate adjusted $^{d}$ & $0.99(0.73-1.35)$ & 1.00 & $0.73(0.51-1.05)$ & $0.92(0.58-1.47)$ & $0.64(0.38-1.09)$ & - & 0.110 \\
\hline
\end{tabular}

a 1 drink corresponds to 12 grams of pure alcohol

${ }^{\text {b }}$ Upper category for women was $21+$ drinks per week

${ }^{\mathbf{c}} P$ for trend: Median values within categories analyzed continuously

dAdjusted for age, smoking, school education, BMI, waist circumference, physical activity, intake of fruit, vegetables, fish, fat and saturated fat, hypercholesterolemia, diabetes, and for women: menopausal status and use of HRT 
Table 3 Hazard ratios (95\% Confidence Intervals) for acute coronary syndrome according to hypertension status and amount of alcohol intake in men and women

\begin{tabular}{|c|c|c|c|c|c|c|c|}
\hline & \multicolumn{6}{|c|}{ Alcohol Intake (drinks per week ${ }^{\mathrm{a}}$ ) } & \multirow[b]{2}{*}{$P$ for trend ${ }^{c}$} \\
\hline & $<1$ & $1-6$ & $7-13$ & $14-20$ & $21-27 / 21+{ }^{b}$ & $28+$ & \\
\hline \multicolumn{8}{|l|}{ Men } \\
\hline \multicolumn{8}{|l|}{ Normal BP $(n=17,313)$} \\
\hline Events $(\mathrm{n}=458)$ & 45 & 148 & 115 & 49 & 42 & 59 & \\
\hline Person-years & 6,577 & 35,068 & 36,847 & 15,612 & 17,496 & 18,942 & \\
\hline Multivariate adjusted§ & $1.33(0.95-1.86)$ & 1.00 & $0.84(0.65-1.07)$ & $0.78(0.56-1.09)$ & $0.58(0.41-0.83)$ & $0.60(0.43-0.84)$ & $<0.001$ \\
\hline \multicolumn{8}{|l|}{ Hypertension(n=8,722) } \\
\hline Events ( $n=402)$ & 35 & 103 & 82 & 58 & 48 & 76 & \\
\hline Person-years & 2,751 & 14,843 & 15,609 & 7,695 & 9,189 & 14,864 & \\
\hline Multivariate adjusted $^{d}$ & $1.73(1.17-2.57)$ & 1.00 & $0.79(0.58-1.06)$ & $1.11(0.80-1.53)$ & $0.82(0.57-1.17)$ & $0.71(0.51-1.01)$ & 0.018 \\
\hline \multicolumn{8}{|c|}{ Women } \\
\hline \multicolumn{8}{|l|}{ Normal BP $(n=21,211)$} \\
\hline Events $(n=134)$ & 29 & 68 & 18 & 13 & 6 & & \\
\hline Person-years & 25,056 & 75,920 & 34,891 & 14,711 & 13,253 & & \\
\hline Multivariate adjusted§ & $0.91(0.58-1.42)$ & 1.00 & $0.64(0.38-1.08)$ & $1.12(0.61-2.06)$ & $0.48(0.20-1.13)$ & & 0.24 \\
\hline \multicolumn{8}{|l|}{ Hypertension $(n=8,216)$} \\
\hline Events $(\mathrm{n}=137)$ & 34 & 62 & 21 & 9 & 11 & & \\
\hline Person-years & 11,014 & 26,280 & 12,562 & 5,949 & 7,041 & & 0.17 \\
\hline Multivariate adjusted $^{d}$ & $1.06(0.69-1.63)$ & 1.00 & $0.81(0.49-1.32)$ & $0.70(0.34-1.47)$ & $0.71(0.36-1.38)$ & & \\
\hline
\end{tabular}

${ }^{\mathrm{a}} 1$ drink corresponds to 12 grams of pure alcohol; ${ }^{\mathrm{b}}$ Upper category for women is $21+$ drinks per week

${ }^{\mathbf{c}} P$ for trend: Median values within categories analyzed continuously

d Adjusted for age, smoking, school education, BMI, waist circumference, physical activity, intake of fruit, vegetables, fish, fat and saturated fat, hypercholesterolemia, diabetes, and for women: menopausal status and use of HRT 
Fig. 1

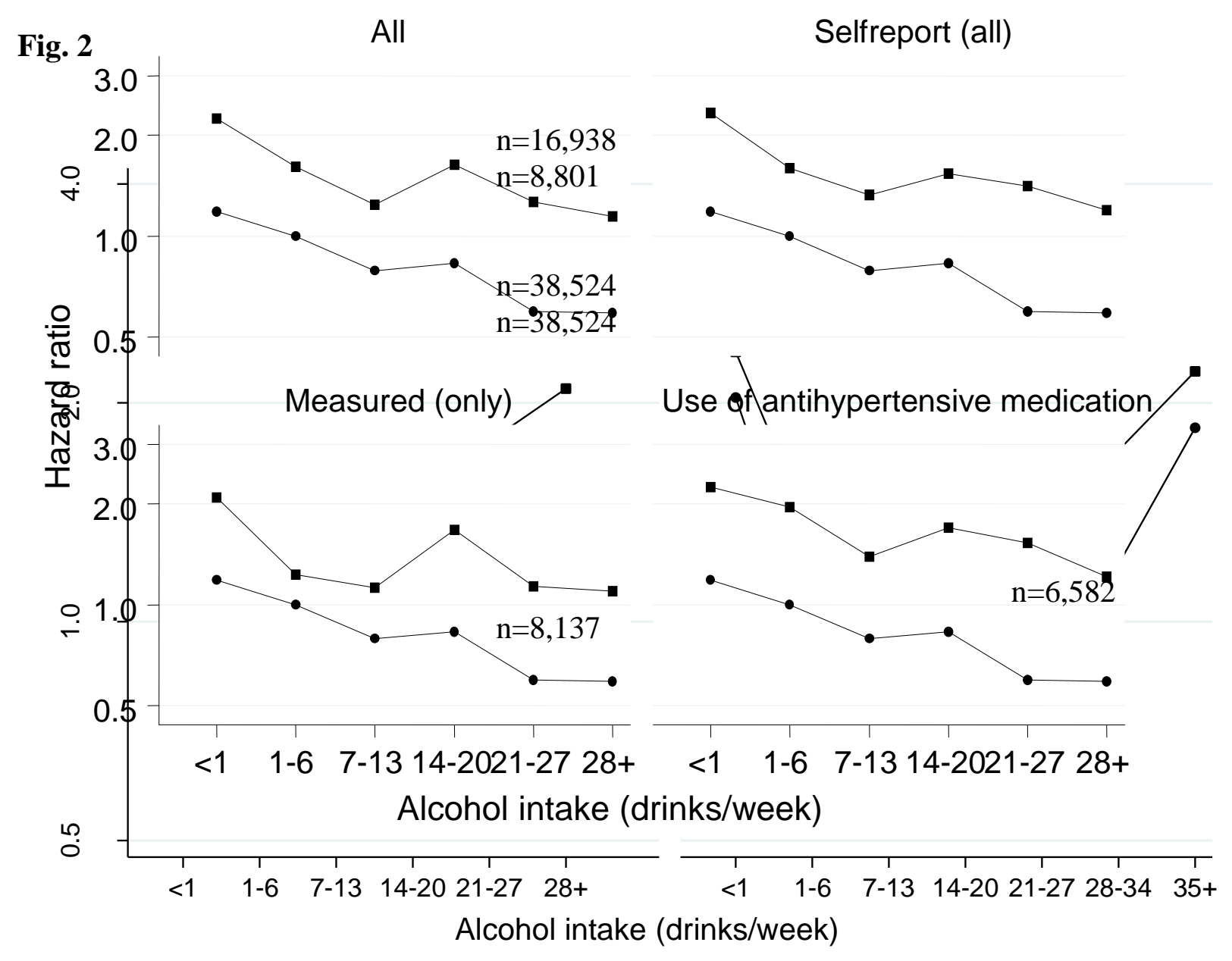

